tube. The abdominal aorta was replaced down to the iliac junction. No postoperative complications were noted. Predischarge computed tomographic scan showed excellent result of thoracoabdominal aorta replacement (Figure 2).

\section{DISCUSSION}

A multicenter investigation of the hybrid endoprosthesis for obliteration of the false lumen in the downstream thoracic aorta has reported the feasibility and efficacy of this approach, with a $25 \%$ rate of distal aortic reintervention at midterm follow-up. ${ }^{4}$ The published reports scarcely discuss the optimal management for further intervention on the downstream aorta. The connective disorder of our patient was likely a determinant of subsequent aortic enlargement, despite successful positioning of hybrid endoprosthesis and even though we did not oversize the prosthesis more than $10 \%$ as recommended. ${ }^{4}$ Moreover, the frequency of patients with Marfan syndrome in the published series is low and does not allow us to draw definitive conclusions regarding the reliability of endoprostheses in this subgroup. Finally, the absence of a distal landing zone before the origin of the visceral vessels and the risk of spinal cord injury ${ }^{5}$ oriented our strategy toward open surgery.

During the thoracoabdominal operation, we unexpectedly localized 3 couples of patent intercostal arteries at the T8 through T10 levels, just near the distal landing zone of the E-vita Open Plus endoprosthesis. The proximal part of the descending aorta was managed under hypothermic circulatory arrest to avoid crossclamping of the stentgraft. On the basis of our institutional expertise with the performance of hypothermic circulatory arrest, we decided to adopt this strategy instead of using a balloon occluder to manage the proximal descending aorta. The distal portion of the stent-graft was resected, and a confident end-to-end anastomosis was performed between the stent-graft stump and a Dacron polyester fabric tube. The stent struts did not at any time present an obstacle to the realization of the anastomosis.

In conclusion, the surgeon should consider the possibility of resecting a portion of the distal stent-graft of the E-vita Open Plus endoprosthesis at the time of open surgery on the thoracoabdominal aorta to perform the proximal anastomosis at the desired level. This may allow a more radical resection of the diseased aortic tissue and the reimplantation of all patent intercostal arteries.

\section{References}

1. Tsagakis K, Pacini D, Di Bartolomeo R, Gorlitzer M, Weiss G, Grabenwoger M, et al. Multicenter early experience with extended aortic repair in acute aortic dissection: is simultaneous descending stent grafting justified? J Thorac Cardiovasc Surg. 2010;140:S116-20; discussion S142-6.

2. Tsagakis K, Pacini D, Di Bartolomeo R, Benedik J, Cerny S, Gorlitzer M, et al. Arch replacement and downstream stent grafting in complex aortic dissection: first results of an International registry. Eur J Cardiothorac Surg. 2011;39: 87-94.

3. Di Bartolomeo R, Di Marco L, Armaro A, Marsilli D, Leone A, Pilato E, Pacini D. Treatment of complex disease of the thoracic aorta: the frozen elephant trunk technique with the E-vita open prosthesis. Eur J Cardiothorac Surg. 2009; 35:671-6.

4. Pacini D, Tsagakis K, Jakob H, Mestres CA, Armaro A, Weiss G, et al. The frozen elephant trunk for the treatment of chronic dissection of the thoracic aorta: a multicenter experience. Ann Thorac Surg. 2011;92:1663-70.

5. Feezor R, Martin T, Hess PJ Jr, Daniels MJ, Beaver TM, Klodell CT, et al. Extent of aortic coverage and incidence of spinal cord ischemia after thoracic endovascular aneurysm repair. Ann Thorac Surg. 2008;86:1809-14.

\title{
A left atrial myxomalike rhabdomyosarcoma
}

\author{
Domenico Corradi, MD, ${ }^{\mathrm{a}}$ Giovanni Andrea Contini, MD,${ }^{\mathrm{b}}$ Tiziano Gherli, MD, ${ }^{\mathrm{b}}$ and \\ Francesco Nicolini, MD, PhD, ${ }^{\mathrm{b}}$ Parma, Italy
}

Cardiac tumors are exceedingly rare, with their frequency being estimated between $0.0017 \%$ and $0.33 \%{ }^{1}$ Despite its limited myocardial mass, the left atrium is

\footnotetext{
From the Section of Pathology, ${ }^{\mathrm{a}}$ Department of Pathology and Laboratory Medicine, and the Heart Surgery Section, ${ }^{\mathrm{b}}$ University of Parma, Parma, Italy.

Disclosures: Authors have nothing to disclose with regard to commercial support.

Received for publication March 18, 2012; accepted for publication March 30, 2012; available ahead of print May 2, 2012.

Address for reprints: Domenico Corradi, MD, Section of Pathology, Department of Pathology and Laboratory Medicine, University of Parma, Via Gramsci 14, 43126 Parma, Italy (E-mail: domenico.corradi@unipr.it).

J Thorac Cardiovasc Surg 2012;144:e7-10

0022-5223/\$36.00

Copyright (c) 2012 by The American Association for Thoracic Surgery

doi:10.1016/j.jtcvs.2012.03.073
}

very frequently involved in both benign and malignant primary cardiac tumors, with polypoid myxoma being the most frequent type. ${ }^{2}$ We report here the exceptional case of a fully polypoid left atrial rhabdomyosarcoma without myocardial infiltration, mimicking a cardiac myxoma.

\section{CLINICAL SUMMARY}

A 39-year-old man was referred to our heart surgery unit because of the recent discovery of a left atrial mass, echocardiographically consistent with cardiac myxoma. The patient's recent medical history had been characterized by such nonspecific symptoms as sporadic fever, 


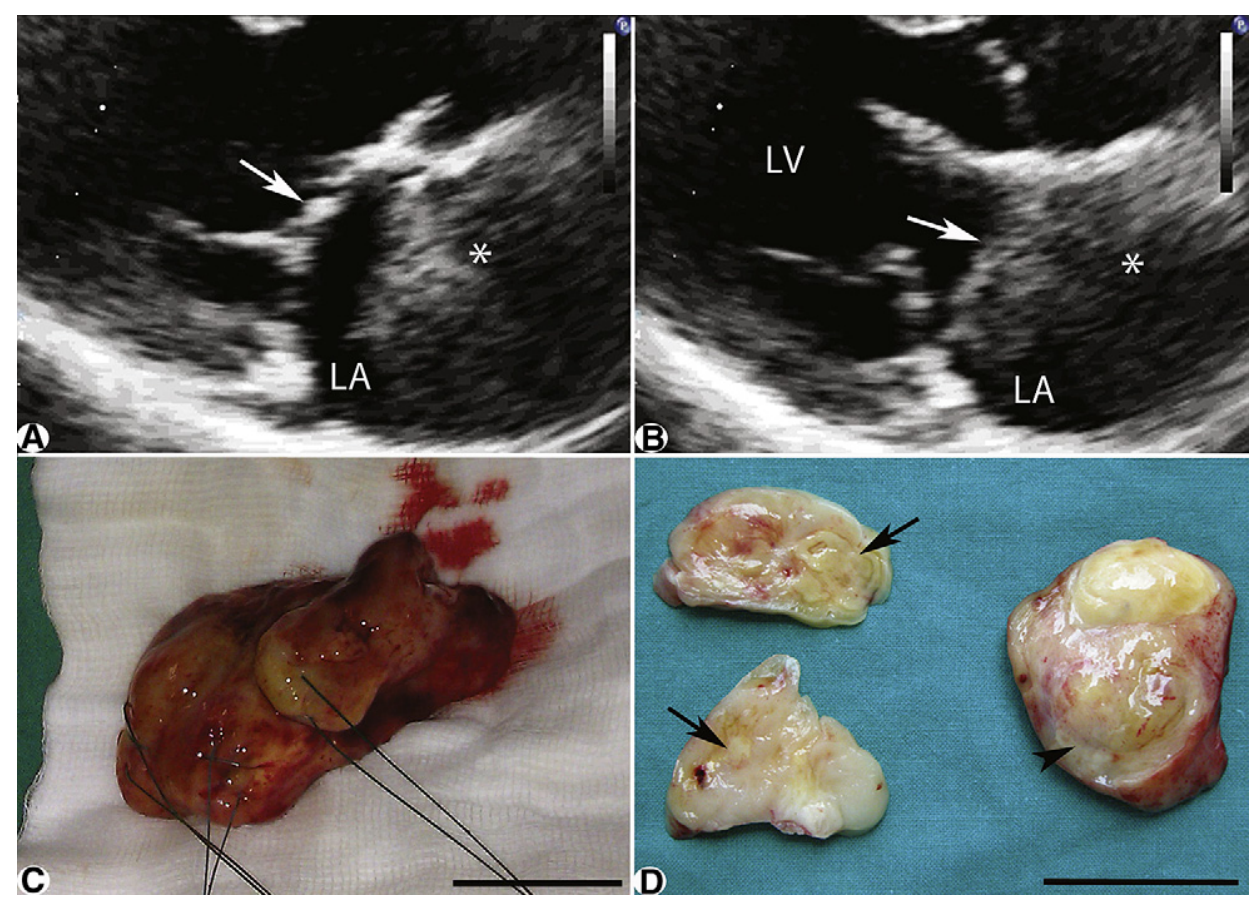

FIGURE 1. A and B, Two-dimensional echocardiography in parasternal long-axis view during systole (A) and diastole (B), showing the sarcoma (asterisks) characterized by nonhomogeneous echocardiographic texture, occupying almost the entire left atrium, and projecting toward the mitral valve plan (arrows) during diastole (B). C, Gross appearance of the bilobular mass. D, Gross transverse sections of the sarcoma. The specimen on the right corresponds to the nonspecific sarcomatous component and shows grayish, yellowish gelatinous nodules and focal necrotic areas (arrowhead). The 2 grayish sections on the left coincide with the rhabdomyosarcoma component and display larger necrotic zones (arrows). $L A$, Left atrium; $L V$, left ventricle. Bars represent $4 \mathrm{~cm}$ in $\mathrm{C}$ and $5 \mathrm{~cm}$ in $\mathrm{D}$.

fatigue, and recurrent episodes of diffuse arthralgia and myalgia.

On admission, heart auscultation revealed regular rhythm with apical systolic murmur (3/6 degrees). Electrocardiography confirmed the sinus rhythm (76 beats/min) with no pathologic signs. A new echocardiogram (Figure 1, $A$ and $B$ ) showed a slightly enlarged left atrium $(45 \mathrm{~mm})$, almost entirely occupied by a lobulated and partially mobile mass that projected toward the mitral valve ostium during diastole, although without significant valve stenosis. The left ventricle was normal, with an ejection fraction of $60 \%$. Emergency surgical removal of the neoplasm was performed and revealed a large, roughly bilobular mass stemming from the roof of the left atrium and the right pulmonary vein outlet.

Grossly (Figure 1, $C$ and $D$ ), this tumor was thymoid and consisted of 2 adjacent and confluent grayish, yellowish masses $(6 \times 4 \times 2.5 \mathrm{~cm}$ and $4 \times 5 \times 2.5 \mathrm{~cm})$ leaning against the underlying resected left atrial wall. The surface of this neoplasm was smooth and seemingly without fragmentation. From a histopathologic standpoint, it showed a biphasic appearance. The tumor's proximal portion (Figure 2, A) stemming from a thickened fibrous endocardial layer and with no microscopic signs of myocardial infiltration (Figure 2, B)—consisted of a nonspecific intermediate- to high-grade, spindle to stellate cell sarcoma (immunohistochemically only positive for vimentin and zonally for smooth muscle actin) with fibromyxoid stroma. Interestingly, this nonspecific component abruptly developed into a high-grade rhabdomyosarcoma (RMS in Figure 2, $C$ and $D)$ with embryonal and focally pleomorphic features, which represented the distal half of the lesion (immunohistochemically positive for the skeletal muscle markers desmin and myogenin and negative for S100, CD34, and CD99). This second component displayed a higher mitotic count (as much as 50 per 10 high-power fields) and larger necrotic areas. The surgical margins were wide.

Although staging examinations showed no secondary lesions, chemotherapy was initiated because the tumor was high grade. Five months after surgery, this patient is without signs of disease.

\section{DISCUSSION}

Cardiac tumors are great masqueraders of a number as other cardiac diseases because they can lead to systemic, 


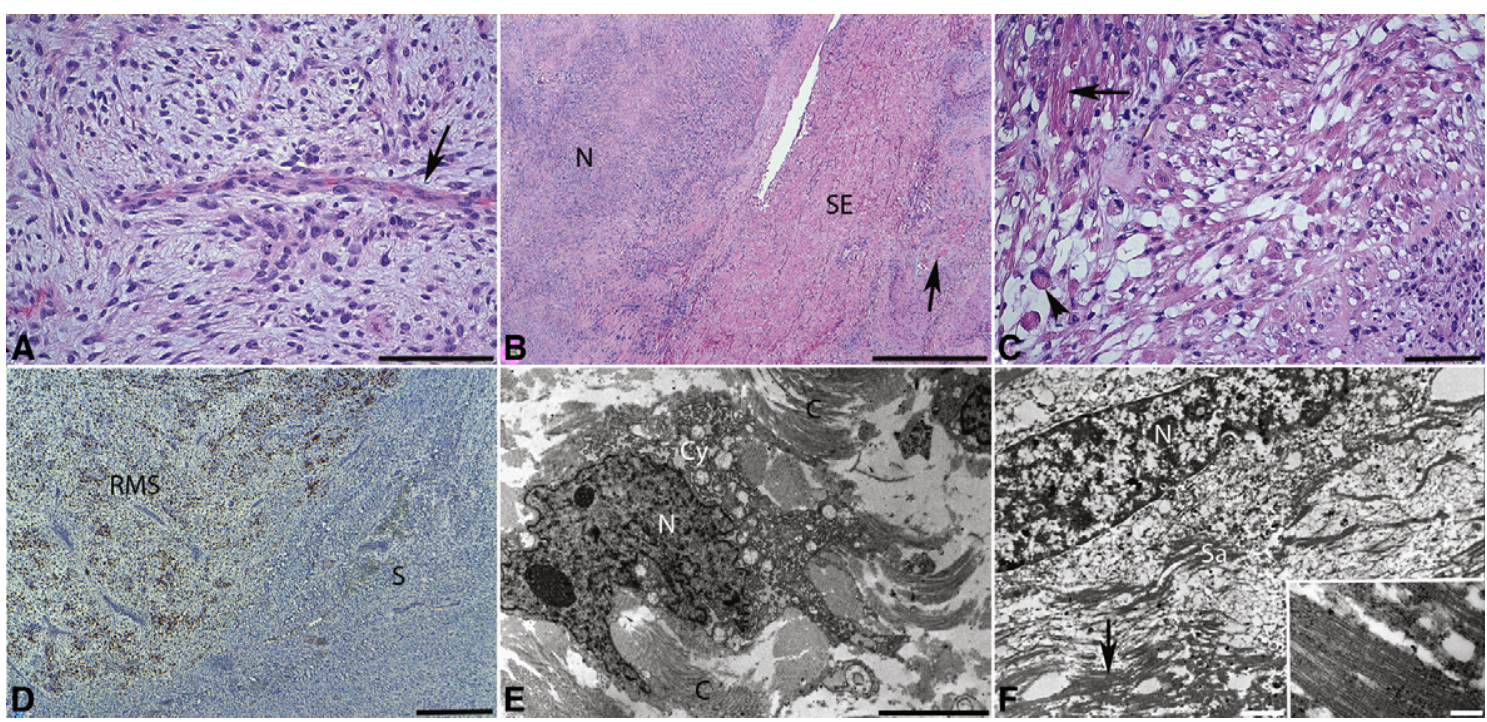

FIGURE 2. A, Histopathologic view of the nonspecific sarcoma, composed of spindle and stellate cells that often crowd around blood vessels (arrow). B, Low-magnification appearance of the tumor proximal portion $(N)$, which stems from a thickened fibrous subepicardium $(S E)$ with no infiltration of the underlying myocardium (arrow). C, Microscopic view of the high-grade rhabdomyosarcoma component, with several elongated (arrow) and rounded (arrowhead) rhabdomyoblasts. D, Immunohistochemical analysis with an antimyogenin primary antibody (a skeletal muscle-specific transcription factor) showing the boundary line between nonspecific sarcoma $(S)$ and myogenin-positive rhabdomyosarcoma $(R M S)$. E, Ultrastructure of a stellate cell belonging to the nonspecific sarcomatous component. The nucleus $(N)$ is highly irregular and atypical; the cytoplasm $(C y)$ contains a number of mitochondria and vesicles. The stroma is myxoid with numerous bundles of collagen type $\mathrm{I}(C)$. There are no contractile structures. F, Electron microscopy of an exceedingly atypical rhabdomyoblast in which the sarcoplasm $(\mathrm{Sa})$ is filled with disorganized and nonfunctioning myofibrillar fragments (arrow and insert). Stains: A, B, and C, hematoxylin-eosin; D, 3,3-diaminobenzidine-revealed immunohistochemistry with mild Harris hematoxylin counterstaining. Original magnifications: A and $\mathrm{C}, \times 20$; B and D, $\times 4$; E, $\times 3500$; F, $\times 7,100$ (insert $\times 56,000$ ). Bars represent $150 \mu \mathrm{m}$ in A and C, $500 \mu \mathrm{m}$ in B and D, $5000 \mathrm{~nm}$ in E; and 2000 $\mathrm{nm}$ in $\mathrm{F}$ (bar in insert represents $200 \mathrm{~nm}$ ).

embolic, cardiac, and metastatic manifestations. About $75 \%$ of all primary cardiac tumors are benign, with myxoma accounting for about half of them. The remaining $25 \%$ are malignant, and about $50 \%$ to $75 \%$ of these are sarcomas, with angiosarcoma, rhabdomyosarcoma, and leiomyosarcoma the most common in order of frequency. Rhabdomyosarcoma, which can arise anywhere in the heart, is the most frequent cardiac sarcoma in the first and second decades of life (with a slight male predominance), although it also may occur in young adults. ${ }^{3,4}$ Prognostic features in cardiac sarcomas are nonspecific: high mitotic activity, extensive tumor necrosis, grading, and the degree of pericardial or myocardial infiltration. ${ }^{1}$

The case under discussion is peculiar in that this large sarcoma was solely intracavitary, with no histologic sign of myocardial extension, whereas previously reported cardiac rhabdomyosarcomas have exhibited frequent and extensive mural infiltration. Curiously, its proximal portion was phenotypically a nonspecific moderate- to high-grade sarcoma that, in the central and distal parts of the mass, had differentiated into a true high-grade rhabdomyosarcoma, as was confirmed both ultrastructurally and immunohistochemically (Figure 2,E and $F$ ). The distance of this more aggressive neoplasm from the base of the lesion may have been the reason for its growth toward the atrial chamber, as well as its sparing of the myocardial layer. Although survival from diagnosis is less than 1 year in the great majority of infiltrating rhabdomyosarcomas, ${ }^{3}$ in this patient, the main potential tumor dissemination route theoretically would have been through the left cardiac chambers and the downstream systemic blood flow. Conceivably, this unusual behavior was the main reason for the original echocardiographic suspicion of benign cardiac mxyoma. Finally, the clinical history of this patient had been characterized by episodes of polyarthritis, which significantly have formerly been reported as possible paraneoplastic events in cardiac rhabdomyosarcoma, along with hypertrophic osteoarthropathy, amyloidosis, neurofibromatosis, eosinophilia, and bilateral mammopathy. ${ }^{5}$

\section{References}

1. Burke A, Tazelaar H, Butany J, El-Demellawy D, Loire R, Geva T, et al. Cardiac sarcomas. In: Travis W, Brambilla E, Muller-Hermelink H, Harris C, eds. Pathology and genetics of tumours of the lung, pleura, thymus and heart. Lyon: IARC Press; 2004. p. 273-81. 
2. Perchinsky MJ, Lichtenstein SV, Tyers GF. Primary cardiac tumors: forty years' experience with 71 patients. Cancer. 1997;79:1809-15.

3. McManus B. Primary tumors of the heart. In: Bonow R, Mann D, Zipes D, Libby P, Braunwald E, eds. Braunwald's heart disease: a textbook of cardiovascular medicine. Philadelphia: Elsevier-Saunders; 2011. p. 1638-50.
4. Burke A, Virmani R. Tumors of the heart and the great vessels. Washington, DC: American Registry of Pathology; 1996.

5. Grandmougin D, Fayad G, Decoene C, Pol A, Warembourg H. Total orthotopic heart transplantation for primary cardiac rhabdomyosarcoma: factors influencing long-term survival. Ann Thorac Surg. 2001;71:1438-41.

\title{
Extra-anatomic pulmonary artery bypass for main pulmonary artery stenosis caused by neoplasm
}

\author{
Ryo Aeba, MD, ${ }^{\mathrm{a}}$ Hiroaki Nomori, MD, ${ }^{\mathrm{b}}$ and Ryohei Yozu, MD, ${ }^{\mathrm{a}}$ Tokyo, Japan
}

Currently, tumor-related pulmonary artery obstruction is most often treated with the percutaneous stenting technique $^{1-3}$; however, this technique is not indicated for patients with tumors situated in close proximity to the pulmonary valve. We present here such a case, that of a patient who had adenoid cystic carcinoma of trachea that recurred at pulmonary artery near the pulmonary valve and who underwent surgical management with an extra-anatomic pulmonary artery bypass.

\section{CLINICAL SUMMARY}

In November 2010, a 51-year-old man with a malignant thoracic tumor was referred to our hospital for management of pulmonary stenosis at the main pulmonary artery level as a result of tumoral invasion. The patient had previously had a tracheal adenoid cystic carcinoma diagnosed and treated with surgical resection and postoperative radiation therapy (56 Gy) in 1999 at another hospital. The malignant tumor was not curable, and the patient had been followed up thereafter. In October 2010, the patient reported shortness of breath while walking. Transthoracic echocardiography demonstrated a mass causing compression of the main pulmonary artery immediately $(<2 \mathrm{~mm})$ distal to the sinotubular junction of the pulmonary valve. Continuous-wave Doppler echocardiography showed a peak systolic gradient of $85 \mathrm{~mm} \mathrm{Hg}$ in the pulmonary artery at the site of compression. The right ventricle was hypertensive and compressed the left ventricle. Cardiac catheterization also showed right ventricular hypertension at 103/11 $\mathrm{mm} \mathrm{Hg}$.

From the Divisions of Cardiovascular Surgery ${ }^{\mathrm{a}}$ and General Thoracic Surgery, ${ }^{\mathrm{b}}$ Keio University, Tokyo, Japan.

Disclosures: Authors have nothing to disclose with regard to commercial support.

Received for publication March 2, 2012; accepted for publication April 4, 2012; available ahead of print May 2, 2012.

Address for reprints: Ryo Aeba, MD, Division of Cardiovascular Surgery, Keio University, 35 Shinanomachi, Shinjuku, Tokyo 160-8582, Japan (E-mail: aebajp@ gmail.com).

J Thorac Cardiovasc Surg 2012;144:e10-1

0022-5223/\$36.00

Copyright (C) 2012 by The American Association for Thoracic Surgery doi:10.1016/j.jtcvs.2012.04.005
In February 2011, the patient underwent an open surgical intervention through a midline sternotomy. The mass was firmly adherent to the ascending aortic wall and pericardium. Cardiopulmonary bypass was established. Under the conditions of an empty, beating heart, the pulmonary trunk was opened transversely at the level of the sinotubular junction. Another pulmonary arteriotomy was created in the anterior aspect of the right branch pulmonary artery, between the ascending aortic and the superior vena caval crossings. A polytetrafluoroethylene tube graft $18 \mathrm{~mm}$ in diameter (W.L. Gore \& Associates, Flagstaff, Ariz) was tailored and interposed between the 2 pulmonary arteriotomies in an extra-anatomic manner, immediately anterior to the ascending aorta.

The patient stayed in the intensive care unit for 1 day after the operation. His recovery was uneventful, and he was free

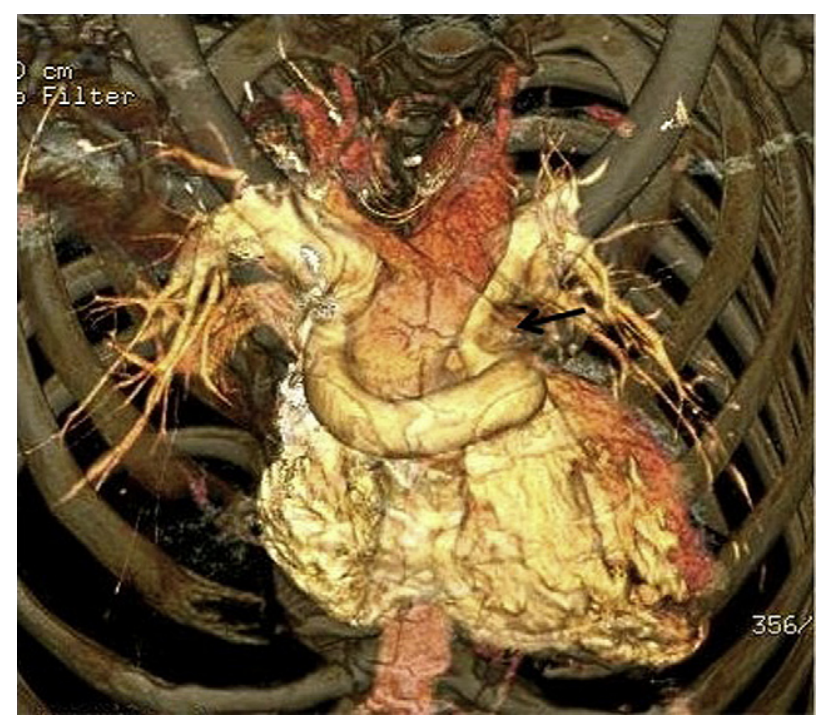

FIGURE 1. Contrast-enhanced multidetector computed tomographic scan 2 weeks after surgery. Three-dimensional volume-rendered image demonstrates an unobstructed tube graft with an extra-anatomic position, bypassing the main pulmonary artery obstruction caused by the tumor (arrow). 